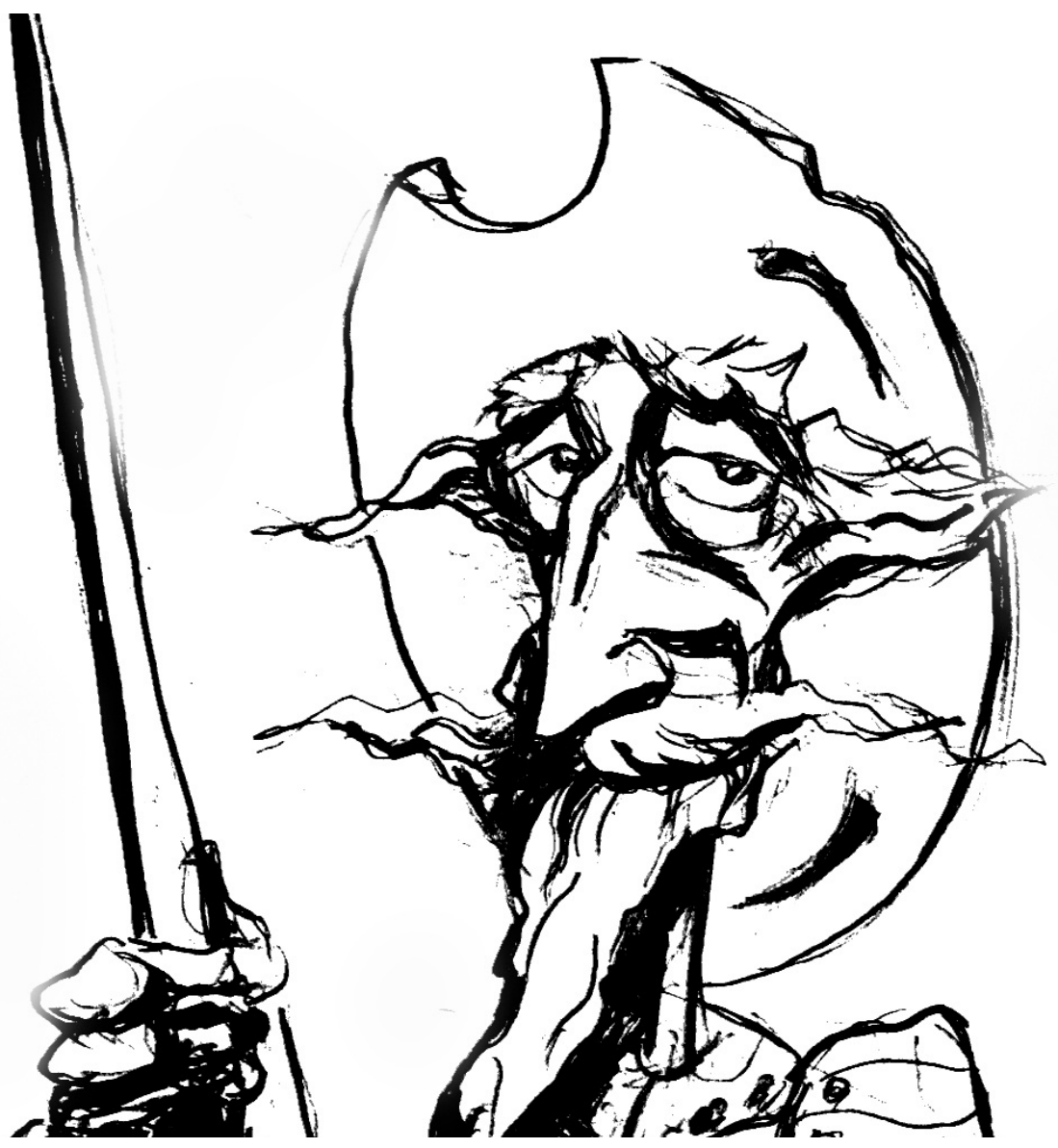

"Parece imitaban los indios a los antiguos". Especies vegetales y bebidas del Nuevo Mundo en las obras de Juan de Cárdenas y Antonio de León Pinelo

[Matías Álvarez] 



\title{
"Parece imitaban los indios a los antiguos". Especies vegetales y bebidas del Nuevo Mundo en las obras de Juan de Cárdenas y Antonio de León Pinelo*
}

\author{
"It seems that the Indians imitated the ancient ones". Vegetable Species and \\ Drinks from the New World in the Works of Juan de Cárdenas and Antonio \\ de León Pinelo.
}

MATÍAS ÁLVAREZ

\section{Resumen}

La modernidad temprana fue testigo de la emergencia de un complejo entramado de circulación de ideas y construcción de saberes acerca del Nuevo Mundo. Viajeros, cronistas y misioneros desarrollaron una literatura de viajes acerca de la alteridad natural y cultural americana. El presente escrito, busca aportar al conocimiento de dicho proceso a partir del análisis de dos tratados: Problemas y secretos maravillosos de las indias del médico Juan de Cárdenas publicado en 1591 y Cuestión moral: si el chocolate quebranta el ayuno eclesiástico del cronista de indias Antonio de León Pinelo publicado en 1636. El eje interpretativo propuesto para abordar estas obras es el análisis de los dispositivos intelectuales que despliegan en relación a las bebidas y plantas del Nuevo Mundo.

Palabras clave

Expansión Ultramarina; Bebidas Americanas; Historia Natural; Alteridad.

\begin{abstract}
Early modernity witnessed the emergence of a complex network of ideas and knowledge about the New World. Travelers, chroniclers and missionaries developed a travel literature about American natural and cultural alterity. The present writing seeks to contribute to the knowledge of this process through the analysis of two treaties: Problemas y secretos maravillosos de las indias of Juan de Cárdenas, published in 1591 and Cuestión moral: si el chocolate quebranta el ayuno eclesiástico of the chronicler of the Indies Antonio de León Pinelo, published in 1636. The interpretative axis proposed to approach these works is the study of the intellectual devices displayed by the authors, in relation to the drinks and plants of the New World.
\end{abstract}

Keywords

Overseas Expansion; American Drinks; Natural History; Alterity.

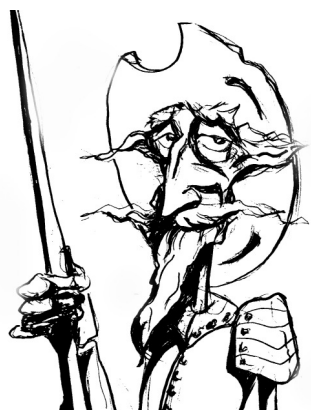

Recibido con pedido de publicación el 15 de febrero de 2020

Aceptado para su publicación el 24 de abril de 2020

Versión definitiva recibida el 15 de junio de 2020

Matías Álvarez, Becario doctoral en la Agencia Nacional de Promoción Científica, Universidad Nacional de Luján, Luján, Argentina; e-mail: alvarezmati@gmail.com

* Agradezco las sugerencias y comentarios de los evaluadores anónimos de la revista.

Esta obra se publica bajo licencia Creative Commons. Atribución-NoComercial-CompartirIgual (cc) EY-No-sa 4.0 Internacional

Álvarez, Matías “'Parece imitaban los indios a los antiguos'. Especies vegetales y bebidas del Nuevo Mundo en las obras de Juan de Cárdenas y Antonio de León Pinelo", Prohistoria, Año XXIII, núm. 34, dic. 2020, pp. 105-130. 


\section{Introducción ${ }^{1}$}

La conquista y colonización de América significó un hecho crucial para la cultura europea de la temprana modernidad. El carácter del Nuevo Mundo, los secretos encerrados en su geografía, su naturaleza y sus habitantes supusieron en sí mismo una ampliación del horizonte de lo real y de lo imaginario. El universo de lo pensable para la cultura letrada moderna se había ensanchado en el proceso de expansión ultramarina. El Nuevo Mundo representó una cantera inigualable para los pensadores de la época y desafiaba el acervo de conocimientos heredado de los clásicos frente a realidades nunca antes relatadas que necesitaban ser ordenadas, conocidas y controladas desde los dispositivos de saber occidentales. La convergencia de discursos como la filosofía natural, la medicina y el discurso teológico, desde sus respectivas prácticas y representaciones, sirvieron como dispositivos para traducir y posicionar las novedades de tierras lejanas al calor de la exploración ultramarina y la conquista.

En esta dirección, los escritos Problemas y secretos maravillosos de las Indias y Cuestión moral. Si el Chocolate quebranta el ayuno eclesiástico, del médico Juan de Cárdenas y del cronista de indias Antonio León de Pinelo respectivamente, dan cuenta de la necesidad de época para abarcar y resolver las polémicas relativas a la emergencia de poblaciones y geografías hasta ese entonces desconocidas y novedosas. Hay que tener en cuenta, tal como señaló Cañizares Esguerra, que la lucha por el Nuevo Mundo en el imaginario de los españoles obedecía a una lucha entre lo divino y lo diabólico. En esta lucha la naturaleza americana era una de las arenas de disputa (Cañizares Esguerra, 2007: 167-169). En efecto, las plantas, la farmacopea y las bebidas del Nuevo Mundo fueron un punto de interés para estos escritores de la temprana modernidad. ${ }^{2}$ En este artículo nos proponemos analizar cómo fueron representadas estas materias tratando de destacar que estos abordajes excedían el plano de un análisis clasificatorio natural. ${ }^{3}$ Provenientes de un universo cultural fuertemente normativizado por

\footnotetext{
${ }^{1}$ Aclaración: En las citas de ambos tratados que transcribimos en el artículo se ha modernizado la ortografía.

2 Tal como señalan Cook y Walker no hay que perder de vista que los conocimientos locales sobre farmacopea en las zonas de contacto colonial permitieron la supervivencia de los viajeros, en un marcado intercambio cultural, que además estaba direccionado por un interés muy concreto en la conformación de redes comerciales en torno a estos materiales. (Cook y Walker, 2013).

${ }^{3}$ Disentimos con Pagden en su interpretación acerca de las descripciones de la naturaleza americana cuando afirma que estas: "no compromete al observador más que a la más superficial evaluación de lo que tiene delante de él. Al fin y al cabo, pocas personas se sienten personalmente comprometidas en las frutas tropicales o en los árboles exóticos. Pero cuando se acercan a acciones de miembros de su propia especie, los hombres exponen mucho de sí
} 
el cristianismo, estos autores encuentran un Nuevo Mundo donde falta determinación frente a materias naturales y bebidas, fundamentalmente porque en estas hay un sustrato lindero de saberes y prácticas indígenas. Por lo tanto, estos tratados y sus autores operan como traductores de una alteridad natural pero también cultural, recurriendo a múltiples dispositivos en su intento por ordenar y apropiar aquello que el Nuevo Mundo y sus habitantes ponían frente a ellos.

Por parte de la historiografía que analizó el impacto que tuvo la emergencia del Nuevo Mundo en la cultura del Renacimiento se han sostenido posturas encontradas. Por ejemplo, Elliott propuso que el impacto del descubrimiento fue limitado y existieron continuidades con las concepciones de los conocimientos establecidos por los autores clásicos de la antigüedad (Elliott, 1976). Distinto es el enfoque de Greenblatt quien, a partir de analizar el asombramiento de los viajeros y exploradores del Nuevo Mundo, propuso una visión más bien rupturista (Greenblatt, 2008). Por otro lado, Grafton sostuvo que hay líneas de ruptura en las que se fueron diluyendo los conocimientos heredados de los clásicos. En este sentido, son sugerentes las afirmaciones de Grafton quien argumenta acerca de cómo este acervo de conocimientos heredados no era una totalidad coherente $y$, por lo tanto, era susceptible de ser administrado en formas variables (Grafton, 1992). Es decir, que podían ser poderosos modelos y combinarse con las nuevas noticias provenientes de la expansión ultramarina, provocando rupturas o constataciones. $\mathrm{O}$ sea pudieron ser simultáneamente herramientas y obstáculos para comprender una realidad que se ampliaba. También Kupperman propone al igual que Grafton una visión más compleja de los múltiples estratos de la conciencia europea (Kupperman, 1995). ${ }^{4}$

Las obras de los autores que analizaremos en este escrito, Juan de Cárdenas y Antonio León de Pinelo, comparten el carácter de viajeros entre ambas márgenes del Océano Atlántico. Oriundos de la Península ibérica, ambos marchan a temprana edad hacia las Indias Occidentales en donde desarrollan sus estudios. A diferencia de León de Pinelo, la vida de Juan de Cárdenas resulta menos conocida y no se sabe mucho más que aquello que él mismo

mismos. Después de todo clasificar hombres no es como clasificar plantas. Porque, al considerar su propia especie, el observador no solo tiene que decidir lo que está viendo, sino también encontrar un lugar para ello en su propio mundo". (Pagden, 1988: 33).

4 Realizar un estado del arte que incluya la amplísima bibliografía sobre el impacto del Nuevo Mundo en el imaginario occidental excede las posibilidades de este artículo debido a la extensión que requeriría. De tal forma solamente mencionamos algunos trabajos con los que dialogamos en este escrito. Cabe señalar que en relación a las materias naturales del Nuevo Mundo la obra del historiador José María López Piñero y su equipo en la Universidad de Valencia fueron quienes primeramente abordaron estos temas en detenimiento y sentaron una línea de estudio donde desde hace algunas décadas convergen distintas agendas historiográficas. 
aporta en Problemas y secretos. Los estudios de Cárdenas transcurrieron en Nueva España donde se graduó de bachiller en medicina en 1584, adquirió el grado de licenciado en medicina en 1589 y el de doctor en medicina en 1590. Su tratado Problemas y secretos salió a la luz en Nueva España en el año de 1591. En él, Cárdenas trata de dar a conocer al público no especializado un abanico amplio de temas que van desde la geografía de las Indias Occidentales, su fauna y flora, hasta la complexión de los nativos. En palabras del propio Cárdenas, el objetivo de su escrito es: "sacar a la luz las misteriosas grandezas de esta fértil, grandiosa y opulenta tierra" (Cárdenas, [1591] 1988: 110). Desde una mirada anclada en la medicina y la filosofía natural del Renacimiento, abarca variados secretos y problemas contenidos en la naturaleza, haciendo aportes también como testigo vivencial acerca de los fenómenos que describe.

La vida de Antonio de León Pinelo resulta más conocida y mejor documentada. Su juventud transcurrió en América, más precisamente en Lima, para luego regresar a España en 1622, donde escribió acerca del Nuevo Mundo en distintos tratados. En Cuestión moral publicado en Madrid en 1636, Pinelo analiza en forma principal el ayuno eclesiástico en relación con una bebida de origen indígena: el chocolate. La controversia en torno a si el consumo del chocolate quebrantaba o no el precepto del ayuno, resultaba para la época un punto de discusión que dividía las opiniones tanto de médicos como de teólogos. La indefinición también se trasladaba a los cristianos aficionados a esta bebida tanto en América como en Europa. En este sentido, la obra concentra sus esfuerzos en probar de manera definitiva cuál era la opinión correcta y cuál era el lugar que debe tener el consumo del chocolate en relación con el dogma y el derecho canónico que regían la vida de los fieles católicos. ${ }^{5}$

Si bien el escrito de Pinelo trata en forma nodular la polémica en torno al chocolate, va más allá al incorporar a la problemática del precepto del ayuno distintas bebidas y preparaciones que se usan en América. Afirma Pinelo: "Y porque mi deseo es siempre declarar más de las materias de las indias, que de otras algunas, así por ser de ellas más noticias y estudio, como por hallarles menos tratadas sabidas" (Pinelo, 1636: 34). En efecto, el aporte del escrito de Pinelo a la historia natural resulta sumamente interesante ya que al tratar de bebidas propiamente americanas debe adentrarse en sus confecciones y, por lo tanto, en los materiales implicados en su preparación, así como también en los usos, orígenes y pertinencia de estas bebidas al precepto del ayuno. También, Juan de Cárdenas, en la segunda parte de Problemas y secretos, aborda las propiedades de plantas, frutas y bebidas americanas con el objetivo de dar a conocer su utilidad medicinal, sus efectos y distintos usos. Coinciden ambos autores en que el Nuevo Mundo encerraba un tesoro natural que era necesario

\footnotetext{
${ }^{5}$ Acerca del chocolate se han escrito muchísimos trabajos. Por razones de espacio y por no ser el tema central de este artículo omitimos las referencias a estos trabajos. Un texto muy importante sobre el chocolate (y también el tabaco) es: Norton (2008).
} 
descifrar inscribiéndose así, a su manera, en el género de las historias naturales del Nuevo Mundo (Pardo-Tomás, 2002). En el caso de Pinelo, el abordaje de la novedad americana buscará principalmente someter distintas bebidas a las reglas eclesiásticas de la penitencia y la templanza, contrarias a los pecados de la gula y la lujuria. En el caso de Cárdenas, su interés apuntará a descifrar los efectos y propiedades de plantas y bebidas para determinar su utilidad en la farmacopea renacentista. Uno y otro, con puntos de contacto y diferencias, son exponentes de "las prácticas representacionales que los europeos llevaron a América y que utilizaron cuando intentaron describir para sus compatriotas lo que veían y hacían." (Greenblatt, 2008: 30).

\section{Juan de Cárdenas frente a las plantas y bebidas del Nuevo Mundo}

Problemas y secretos maravillosos de las indias forma parte de un conjunto de relatos conocido como literatura de secretos (Pardo-Tomás, 2004). Este tipo de escritos desde la filosofía natural, la historia natural y la medicina, apuntaba a dar a conocer a un público amplio y en un lenguaje accesible aquellas ocultas y extraordinarias propiedades del orden natural. En el contexto de los viajes interoceánicos, la literatura de secretos ampliaba su espectro con la circulación de relatos, informaciones y maravillas desde las cuatro partes del mundo.

La curiosidad y el asombro del joven médico sobre el uso de plantas y bebidas de las Indias Occidentales lo llevan a reflexionar y dedicarles la segunda parte de su tratado. Acerca del tesoro natural de las tierras americanas sostiene que sobrándole maravillas y secretos: "solo faltaron escritores que ilustrasen y engrandeciesen sus cosas" (Cárdenas, [1591] 1988: 33). Y más adelante afirma: "contaré, con verdad y certísimo testimonio de gente que la ha visto cosas que si solo las oyera Plinio, quedará absorto y espantado" (Cárdenas, [1591] 1988: 35). ${ }^{6}$ Justamente un punto común en este tipo de escritos, que en el caso de Cárdenas adquiere una claridad meridiana, es la consciencia de que las materias tratadas son muchísimas pero, además, son nuevas en el sentido de que no fueron abordadas por los autores clásicos. Si bien hay una incondicionalidad a los conocimientos y la autoridad de los clásicos, la construcción de una autoridad en el relato de Cárdenas se funda en

\footnotetext{
${ }^{6}$ Es interesante la cita anterior ya que conjuga varias cuestiones. La veracidad derivada de los testigos visuales, la referencia a los clásicos y al mismo tiempo la dimensión del asombro. Esta última está proyectada discursivamente hacia los clásicos, en este caso Plinio, quien quedaría "absorto y encantando" de saber aquellas noticias con las que convive Cárdenas. Sin embargo, el asombro de Plinio es figurativo ya que estas materias nunca llegaron a sus oídos, nunca pudieron ser tratadas por él y de tal forma Cárdenas recobra un protagonismo potenciado en la medida en que es él quien puede traducir lo disímil que se encuentra en el Nuevo Mundo, en una retórica de la alteridad producto del asombro previamente proyectado en Dioscórides. Sobre los relatos en torno a la alteridad, dos trabajos a los cuales haremos referencias en este escrito son: (Hartog, 2002; Greenblatt, 2008).
} 
testimonios de primera mano como una vía de acceso privilegiada, debido a su contacto directo con las realidades retratadas. ${ }^{7}$ Este procedimiento, en términos de Hartog, es una traducción entre el aquí (Europa) y el allá (América) que permitía generar credibilidad a partir de un efecto de realidad del relato (Hartog, 2002: 227). Además, estas noticias, ampliando el universo de lo pensable, convergían en la incorporación de la novedad como pieza cada vez más constitutiva e íntima de validación al interior de estas tramas discursivas que proliferan en los siglos XVI y XVII (Grafton, 1992:3).

Es inevitable no advertir el asombro y zozobra que provocan en Cárdenas la flora, la fauna, la geografía y los nativos del Nuevo Mundo. De acuerdo con Greenblatt, el asombro es un componente ineludible en los discursos sobre el descubrimiento ya que implican un reconocimiento de lo diferente, explorando lo indeterminado y a la vez creando vías de acceso para su posesión y asimilación." (Greenblatt, 2008:60). De tal forma, Problemas y secretos es un escrito que busca dar respuesta a preguntas sobre las cualidades ocultas y secretas del orden natural americano Planteando y discerniendo en la segunda parte del escrito las maravillas y secretos encerrados tanto en plantas y bebidas, no solo por el afán de resolver estos problemas, sino también para dar cuenta de sus usos y sus cualidades medicinales. ${ }^{8}$ Por ejemplo, en el caso de la yuca, se pregunta: "Por qué causa el zumo de la yuca, si lo toma crudo, mata y cosido es de muy buen mantenimiento." (Cárdenas, [1591] 1988: 161). En la misma línea argumentativa, se pregunta acerca del chile: mientras más se tuestan menos calor dan, así como en relación con la coca se pregunta: "por qué trayéndola en la boca dan fuerza o mantenimiento" (Cárdenas, [1591] 1988: 161). Las respuestas giran en torno a la descripción de las partes de la planta, sus propiedades y sus efectos en el cuerpo a partir de una concepción hipocrática galénica. Tal como afirma: “Esto que diré no será invención ni imaginación mía, sino sacado de lo mejor, más verdadero y acendrado que hay en toda la doctrina de Hipócrates y Galeno, ayudándome también de las reglas y preceptos de la filosofía de Aristóteles" (Cárdenas, [1591] 1988: 266).

En el discurso médico de la época de Cárdenas las cualidades de las plantas (caliente / fría / seca / húmeda) se correspondían con los cuatro humores del cuerpo humano (sangre/ flema/ cólera / melancolía). La salud o su falta eran

\footnotetext{
7 Tal como ha señalado Pagden, la mirada autóptica era en realidad una antigua categoría de la retórica que consistía en "la apelación a la autoridad del testigo ocular, al entendimiento privilegiado que aquellos presentes en un acontecimiento podían tener sobre aquellos que sólo habían leído u oído sobre el mismo". (Pagden, 1993: 51). En tal sentido, resinificada a la luz del impacto que el Nuevo Mundo produjo en los criterios de verdad y métodos cognitivos hasta entonces privilegiados, la autopsia se presentó como un mecanismo para crear textos de autoridad sobre temas y lugares de los que nunca antes se había hablado. Quizás uno de los exponentes más representativos de esta mirada autóptica sobre la naturaleza del Nuevo Mundo haya sido el cronista Gonzalo Fernández de Oviedo.

8 Sobre este tema véase: Egaña Rojas (2015); Gruzinski (2010).
} 
interpretadas como el equilibrio o desequilibrio entre estos humores. Desde la medicina se buscaba mantener y restaurar los desequilibrios en los humores mediante el consumo, entre otros elementos, de plantas y bebidas que a partir de sus cualidades conllevaban primeros, segundos y terceros efectos en el cuerpo (Pardo-Tomás, 2002: 78-79). De tal manera, esta operación de disección sobre las nuevas materias provenientes de las Indias Occidentales, develaba la trama de conexiones recíprocas que unían a seres y objetos. Determinando sus efectos, posibilidades y utilidades, el discurso que desarrolla Cárdenas opera traduciendo la novedad cotejándola con los cánones del saber establecido, sea bíblico o clásico, pero también combinado con la primacía de la inmediatez dada por un conocimiento local y una experiencia directa acerca de aquello que se cuenta. ${ }^{9}$

En un sentido general, Cárdenas es un entusiasta de las plantas y bebidas del Nuevo Mundo, pero reconociendo en ellas efectos contradictorios en el cuerpo, por ejemplo respecto al cacao o chocolate para el cual busca: "dar aviso y noticia a todos del modo que deben guardar en usarse sin perjuicio de la salud" para "declarar por qué vía y modo obre y cause el cacao en el cuerpo tan contrarios y no poco notables efectos" (Cárdenas, [1591] 1988: 136). Esta fascinación por los contrarios efectos de las plantas y bebidas americanas, requerían un esclarecimiento desde la filosofía natural. Cárdenas fue contundente al interpelar "al vulgo", al cual atribuía una excesiva credulidad al respecto porque escuchaba:

"decir a cada uno su parecer: unos abominan el chocolate, haciéndolo inventor de cuantas enfermedades hay, otros dicen que no hay tal cosa en el mundo y que con él engordan y traen gana de comer y buen color en el rostro, y si es mujer estéril se hace preñada y la parida, bebiéndole con atole, tiene sobrada leche" (Cárdenas, [1591] 1988: 146).

Las plantas y bebidas, así como las representaciones y prácticas que giraban en torno a ellas, lejos de ser reveladas por los europeos, formaban ya parte de las prácticas culinarias y terapéuticas indígenas. En líneas generales, es sabido que entre los pueblos indígenas no se concebía una división entre la esfera de lo natural propiamente con lo sobrenatural, es decir ambos mundos estaban entreverados sin que ello resulte una contradicción. ${ }^{10}$ En verdad, en el horizonte cultural de Cárdenas, el orden natural y el orden sobrenatural tampoco estaban absolutamente separados, ya que la intervención de agentes de otros órdenes, tales como ángeles o demonios pertenecientes a la esfera

\footnotetext{
9 Tomamos el concepto de traducción de (Grafton, 1992: 3-4). También sobre la combinatoria del testimonio de viajeros, el saber bíblico y clásico véase: (Martínez, 2016). Referido al texto de Cárdenas, Pardo Tomas utiliza el concepto de mediación (Pardo-Tomás. 2011).

10 Sobre este tema la bibliografía etnohistórica y etnográfica es muy amplia. Un trabajo fundamental que refiere a Nueva España es: Aguirre Beltrán (1963).
} 
preternatural, eran consideradas posibilidades concretas para su época (Campagne, 2002; Park-Daston, 1998). En todo caso, lo que la filosofía y la medicina natural buscaban exponer eran las formas de manifestación y acción de lo sobrenatural en el plano natural delimitando ambas esferas, sus posibilidades intrínsecas y relaciones (Foucault, 2008: 13).

\section{Imagen 1}

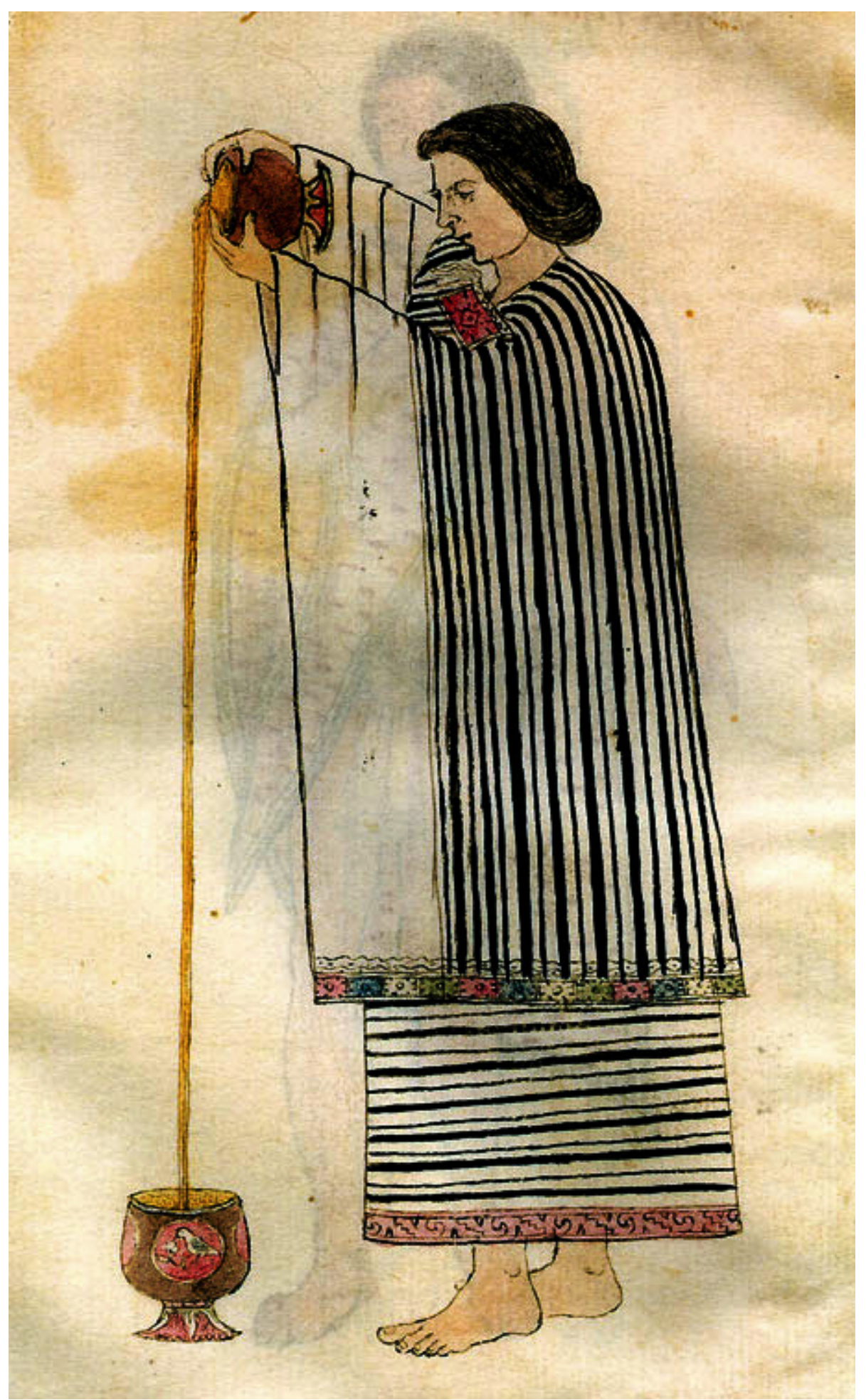


Imagen perteneciente al: Folio 3-r del Códice Tudela, siglo XVI

Cárdenas indaga en las capacidades de las plantas y bebidas desde una mirada hipocrática y omite, en la mayoría de los casos, los usos y significados indígenas de las mismas. A la vez, en su explicación reduce al mínimo las posibilidades de exceder las causalidades del orden natural. Si bien da muestras de un uso propiamente indígena, no profundiza en él, sino más bien estima este tipo de consumo como "bárbaro" o de "gente miserable" (Cárdenas, [1591] 1988: 157-163). En sus explicaciones se reduce la entrada de lo maravilloso o lo extraordinario. Por ejemplo, sobre la coca y el tabaco en relación con el dilema sobre cómo suplen la sed y el cansancio, dando fuerza y vigor a quien las consumiera, evacúa la posibilidad de que dichas plantas mascadas den mantenimiento. Esta afirmación, que circulaba en el mundo colonial y en los tratados de la época, es acusada de equivocada y falsa, para luego desplegar una explicación a partir de los efectos que las flemas desataban embriagando al cerebro y así se evitaba sentir el cansancio y se suplía la falta de sustento y bebida (Cárdenas, [1591] 1988: 165-166). Es bien sabido que en las poblaciones americanas, tanto la coca como el tabaco tenían una relación directa con el universo sobrenatural. Este aspecto hacía de estas plantas sospechosas de hechicería e idolatría. ${ }^{11}$ Sin embargo, Cárdenas concentra su abordaje en el orden natural, es decir sobrepone a un uso indígena, tachado de supersticioso e ilegítimo, una clasificación hacia la naturalización de las hierbas y bebidas despojadas de sus potenciales añadidos idolátricos (Bernand y Gruzinski, 1992: 157 y 168).

Sustraídas de sus aspectos sospechosos de idolatría, las plantas y bebidas americanas son defendidas por Cárdenas con vehemencia -consideradas sumamente útiles- contra aquellos que las rechazan. El tabaco en sus múltiples usos (como bebida, ungüiento, inhalado o fumado) a pesar de su apariencia "infernal", producto de su humo y hedor, resulta de sumo provecho por sus propiedades médicas y es catalogado como "santa yerba" (Cárdenas, [1591] 1988: 194). Un extrañamiento entusiasta atraviesa estas descripciones afirmando que el tabaco es "el más extraño modo de medicina que en toda el arte médica jamás se imagina" y advierte también sobre sus potencialidades para la salud así como sus posibles usos nocivos, legitimando así el saber médico sobre su utilización (Cárdenas, [1591] 1988: 194-195). El relato de Cárdenas adquiere un tono providencial al afirmar que: "puso Dios virtud en las yerbas y cosas de la tierra para conservarse el hombre y librarse de las enfermedades" (Cárdenas, [1591] 1988: 268) y específicamente en las Indias, donde el calor y la humedad flagelan los cuerpos, el tabaco era indispensable. Justamente, la historia natural

\footnotetext{
11 Tanto el tabaco como la coca fueron objetos de numerosas investigaciones. Un trabajo que los toma en conjunto es: Ginzburg (2010: 133). Otro trabajo muy importante es: Norton (2008).
} 
y la medicina resultaban armónicas con el orden cristiano, en la medida en que descifraban las leyes de un orden natural creado por la divinidad. Al menos en el escrito de Cárdenas no se ve una contradicción sino una complementariedad entre ambos discursos.

En esta dirección, el aporte de Cárdenas se vuelve relevante para entender un punto de contacto entre discurso médico y religioso, ya que a fines de desterrar los "errores del vulgo", busca determinar si las bebidas americanas como el chocolate, el pocole, el pinole o la chicha quebrantaban el ayuno religioso. El precepto del ayuno, en el contexto de la contrarreforma tridentina, resultaba un punto de profunda normativización para la vida de los católicos, ya que al reprimir la sensualidad castigando el cuerpo se evitaba el pecado de la lujuria (Ferlan, 2018). La indeterminación de si las novedosas bebidas americanas quebrantaban o no el ayuno, requería esclarecimiento por parte de los representantes de la medicina y la historia natural. Acerca de este punto, Cárdenas sostuvo que el consumo de dichas bebidas en días de ayuno conllevaba su quebrantamiento y, por lo tanto, era pecado. En su opinión, estas bebidas daban sustento y, por lo tanto, apagaban el hambre y daban calor. Siendo solo permitidas, en pequeñas porciones, para aquellos débiles que sufren desmayos y a modo de medicina (Cárdenas, [1591] 1988: 148-149).

Por último, la tercera parte del libro de Cárdenas contrasta con las dos primeras al abordar el uso y los problemas que traen aparejadas materias como:

"el peyote, del poyomate, del hololisque y aun el piciete, que afirman muchos, mayormente indios y negros y gente necia y torpe, de que si estas sobredichas yerbas se toman por la boca, se les presenta y ven al demonio, el cual les dice y declara cosas por venir. Es justo averiguar ahora si alguna hierba o raíz haya en la naturaleza, cuya virtud sea tan eficaz y poderosa que mediante ella forcemos al demonio venga a nuestro llamado o por ella adivinemos alguna cosa por venir." (Cárdenas, [1591] 1988: 274).

Estas plantas, que en la actualidad catalogaríamos como psicotrópicas o alucinógenas, tenían y tienen en las culturas indígenas una correspondencia con las fuerzas sobrenaturales. Muy a grandes rasgos, su consumo heredero del pasado indígena era enmarcado en distintos rituales que proporcionaba la incorporación de la potencia de las divinidades, permitiendo el acceso a la dimensión sagrada (Aguirre Beltrán, 1963: 206). En la argumentación de Cárdenas, los mecanismos de naturalización de los efectos de dichas plantas desde el discurso médico encuentran un límite. Luego de demostrar el carácter supersticioso sobre estos usos a partir del tópico de la idolatría/superstición/hechicería colonial y demarcar los efectos de las plantas en los humores del cuerpo, las cuales cataloga como calidísimas y fuertes, 
encuentra un punto de contacto con un orden de causalidad distinto al natural en las prácticas de consumo de plantas psicotrópicas: “Lo que esto se me ofrece responder es que hay parte de esto en la hierba y parte que solo se debe atribuir al demonio" (Cárdenas, [1591] 1988: 245).

Para Cárdenas el fuerte carácter embriagante de estas plantas marcaba la diferencia con las demás tratadas en el libro, ya que predisponen al contacto con lo sobrenatural indígena, que en la época de Cárdenas desde el discurso teológico se traduce en la esfera de acción de lo demoníaco:

"el demonio, cuando trae ciego y engañado a algún desventurado, le debe aconsejar que use de alguna de estas yerbas, no para que con la virtud de ellas le fuerce venir a su llamado, sino para que con ellas se embriague y salga de juicio y saliendo pueda perder el miedo a una cosa tan horrible [...] y estando así fuera de juicio o medio atónito, viene el demonio a comunicarle y engañarle, diciéndole o respondiéndole a lo que le pide, y ésta es la causa por que los indios sacerdotes de esta tierra, para ver de consultar al demonio, usaban primero tomar el humo del piciete [...] y perdiesen el miedo con la embriaguez" (Cárdenas, [1591] 1988: 276).

El uso de dichas plantas de efecto embriagante, concluye Cárdenas, solo debía ser competencia del saber médico renacentista, siendo rotundamente tachado de ilegítimo en manos de los especialistas indígenas.

\section{Antonio de León Pinelo frente a las bebidas y plantas del Nuevo Mundo}

Cuestión moral. Si el Chocolate quebranta el ayuno Eclesiástico es un tratado enfocado en la polémica sobre el chocolate como bebida y en relación con el ayuno eclesiástico. Las tres partes del tratado giran sobre esta cuestión: poner bajo la lupa de las reglas eclesiásticas concernientes al ayuno y la penitencia a una bebida como el chocolate proveniente del Nuevo Mundo que iba adquiriendo una inusitada popularidad dentro de los dominios del catolicismo de ambos lados del atlántico (Hernández Triviño 2013: 37). La principal forma de acercamiento que establece Pinelo es el probabilismo. ${ }^{12}$ Este es conjugado con

\footnotetext{
12 Acerca del probabilismo Mayer Celis afirma: “El probabilismo es una corriente dentro de la filosofía moral del cristianismo que se desarrolló a partir del siglo XVI. Una característica central del probabilismo es que en él las certezas son imposibles. Además de que esta corriente se configuró como un sistema basado, tanto en fundamentos razonables como en el estudio de
} 
una extensa lista de autores clásicos y modernos tanto de la medicina como de la filosofía natural. Evalúa las distintas opiniones que se sostenían acerca del chocolate y el ayuno, desarrollando un relato acerca del origen de la bebida y sus diferentes formas de preparación, para luego discutir detalladamente cada una y resolver la duda moral. En esta polémica Cárdenas ya había desarrollado su posición en Problemas y secretos y esta es retomada por Pinelo quien incluso incorpora la sección concerniente al chocolate desarrollada por Cárdenas en el apéndice de su tratado. En este sentido, no solo es evidente que Pinelo ha leído la obra de Cárdenas, sino que continúa y se inserta en términos generales dentro de una línea de abordaje de las novedades americanas desde la filosofía natural. También convergen ambos en una concepción del cuerpo humano como una entidad tanto orgánica como espiritual. En el contexto post tridentino, donde el catolicismo busca normativizar y regular cada uno de los aspectos de la vida de los fieles, ambos tratados resultan sintomáticos de las preocupaciones y problemas que implicaba esta novedosa circulación e incorporación de sustancias de carácter planetario.

Tal como anticipamos, el tratamiento del chocolate en Cuestión Moral es el núcleo duro del libro, sin embargo este abordaje se replicará parcialmente en torno a distintas bebidas y plantas americanas tales como el chuñu, el tabaco, el coro, el pulque, el atole, el cebil, la algarroba, la yuruma, la coca o la yerba mate, entre muchas otras. En verdad el tratado va incluso más allá de las bebidas americanas y trae a colación noticias de bebidas de Asia, África y Europa. El despliegue de citas y referencias de Pinelo da cuenta de una erudición innegable que en conjunto con su experiencia americana brindan las bases sobre las cuales construye su conocimiento.

Ya en el prólogo de su tratado, Pinelo delimita la esfera del derecho canónico relativo a las resoluciones morales, y construye un lugar de enunciación donde, a partir de la filosofía natural y su conocimiento de las bebidas americanas, se detendrá en el discernimiento del contacto legítimo e ilegítimo de los fieles católicos con las bebidas americanas. Refiriéndose a los canonistas afirma: "suyas son las revoluciones, míos algunos argumentos, y la disposición, y junta de todos; que servirán de borrador al que con más inteligencia tratare la materia" (Pinelo, 1636: 2). En la argumentación de Pinelo ambas esferas discursivas convergen y se complementan. Las resoluciones morales del derecho canónico, relativas al ayuno eclesiástico, encuentran en Cuestión Moral una argumentación cuyo objetivo principal es someter a las

casos concretos -la casuística- para entender problemas que se encontraban en el campo de la moral. Esta teoría abrió una ranura en el determinismo y permitió el desarrollo de la duda, la incertidumbre y el riesgo moral". (Mayer Celis, 2011). Es sugerente el desarrollo que realiza esta autora, ya que enmarca al probabilismo en la emergencia de distintas dudas morales producto del contacto con otras culturas en el contexto de la primera mundialización. Véase también: Imolesi (2018). 
bebidas americanas a una definición y resolución: "valiéndome de mis noticias, he aplicado la resolución moral a las bebidas principales que ha inventado el arte, o deleite, y usan en las cuatro partes del Mundo, y más en el Nuevo de las Indias" (Pinelo, 1636: 2).

El abordaje sobre el chocolate estará ordenado por un punto central: debatir si "El chocolate como bebida esencial" o si "El chocolate es comida esencial", o sea si la ingesta del chocolate en tanto bebida o comida, es legítimo o ilegítimo en días de ayuno. Discute la poca definición del problema, "los errores del vulgo", y la costumbre extendida de beberlo en días de ayuno sin que se haya resuelto a modo definitivo la cuestión por los doctos. ${ }^{13} \mathrm{Su}$ argumentación descansa en el análisis pormenorizado de tres opiniones: el chocolate es esencial bebida y como tal no quebranta el ayuno eclesiástico, el chocolate es esencial comida y quebranta el ayuno eclesiástico, y por último la opinión de quienes sostenían que en moderada cantidad el chocolate no quiebra el ayuno eclesiástico. Pinelo se inclinará por esta última opinión, argumentando acerca de la "parvidad" de la materia comestible en la bebida (Pinelo, 1636: 99). Aun así, el recorrido del tratado considera cada opinión y sus diversos fundamentos atravesando muchos aspectos inherentes a la preparación y consumo del chocolate. Establece, además, constantes comparaciones con otras bebidas europeas, americanas, asiáticas y africanas. Las herramientas a las que recurre para debatirse con cada opinión son sus amplios conocimientos de filosofía natural, medicina y derecho canónico, puestos en juego con una inagotable cantera de noticias, novedades y curiosidades producto de una vida intelectual atravesada por el proceso de expansión ultramarina. En tal sentido, el escrito tiene un notable carácter de polémica, donde el chocolate funciona, de alguna manera, como una punta de lanza a partir de la cual se despliega un dispositivo de determinación/clasificación de la legitimidad o ilegitimidad del consumo de bebidas y materias naturales en días de ayuno. Este procedimiento de análisis de las características naturales y las propiedades y de las formas de elaboración y consumo, se extiende a una variada lista de bebidas y preparaciones del Nuevo Mundo.

Al igual que Cárdenas en Problemas y secretos, la necesidad de dirimir la admisión, utilidad y características de plantas y bebidas del Nuevo Mundo se vuelve imperiosa en el escrito de Pinelo. En el mundo colonial, la circulación de estos elementos cuyos orígenes se remontaban a "invención de gentiles y bárbaros" (Pinelo, 1636: 16) pone en contacto el universo cultural indígena con el cristiano. Muchas veces la necesidad de la empresa conquistadora extendía un consumo de dichos elementos sin controversia y en algunos casos hasta era admitido como costumbre por su uso corriente y generalizado. Incluso Pinelo menciona cómo el chocolate fue reelaborado por los españoles, quienes le

\footnotetext{
${ }^{13}$ Una interesante síntesis de las controversias en torno al chocolate durante el periodo moderno es: Norton (2008).
} 
añadieron infinitos condimentos y de forma entusiasta declara que el chocolate era: "sustento, regalo y medicina" (Pinelo, 1636: 4).

Pinelo reconoce un origen indígena en el chocolate, así como sus usos como bebida, sustento y las múltiples formas de prepararlo. Este carácter "bárbaro", a juzgar por nuestro autor, es el origen de la confusión, ya que:

“Los indios con su uso no nos pueden dar consecuencia, porque ni ellos guardaban abstinencia de manjares en días ciertos ni se les prohibían ningunos, ni se tenían precepto del ayuno eclesiástico. Luego no podemos hacer argumento de sus comidas ni bebidas, para nuestro uso y religión. Las más naciones de las Indias comían carne humana" (Pinelo, 1636: 16).

Más adelante agrega:

"Aquellos aunque tenían sus gentilicias abstinencias, comían indistintamente todos los días del año los manjares que tenían, sin reparar en que fuesen de carne, o pescado. Por hallar este uso entre ellos podremos quebrantar el precepto de la Iglesia, que nos prohíbe comer carne los días de Viernes, y de ayuno? Claro es que no, sin quedar por más barbaros que ellos". (Pinelo, 1636: 16)

Pinelo también compara e incorpora en su argumentación distintos tipos de ayunos entre pueblos no cristianos y menciona incluso el caso de los lamas del Tíbet, los pueblos indígenas del Perú y también los de Mesoamérica. A todos los casos que trata los define como: "ayunos barbaros, sin forma, ley, ni merito" (Pinelo, 1636: 18). Aun así, concluye que los propios indígenas mesoamericanos, de quienes tomaron los europeos el chocolate, en estos "ayunos de gentiles" se abstenían del consumo del chocolate. Por esta razón argumenta que los españoles: "menos lo debemos usar nosotros que en el ayuno de la Iglesia tenemos lo que en aquellos faltaba" (Pinelo, 1636: 18).

En todo caso, la abstinencia indígena del consumo del chocolate no es tanto un argumento válido para la polémica en la que participa Pinelo sino más bien muestra la sensibilidad que adquiere la cuestión del contacto con estas novedosas bebidas y especies vegetales $\mathrm{y}$, por lo tanto, con un saber indígena que remite a un sustrato cultural extraño al occidental cristiano. En el horizonte cultural de Pinelo difícilmente pudieran pensarse separadamente el estudio del mundo natural en forma aséptica, a las prácticas y representaciones de otros pueblos con ese mismo medio de quienes los europeos tomaban parte. En este sentido, al pensar el mundo natural necesariamente conjuga una clasificación de los propios indígenas y sus prácticas en una etnografía implícita. ${ }^{14}$ Ambas

\footnotetext{
${ }^{14}$ Schwartz propone el concepto de etnografía implícita, que supone un entendimiento selectivo para el abordaje de los contactos culturales (Schwartz, 1994: 2). También Hartog, para el caso de
} 
esferas irremediablemente se representan en conjunto en la argumentación de Pinelo y, si bien ambos universos culturales coincidían en dispositivos normativos acerca de las bebidas, rápidamente descalifica esta semejanza recurriendo las ideas acerca de la barbarie (Corcuera de Mancera, 1997).

Así, el origen y conocimiento indígena de estas bebidas no podía ser una referencia legítima, sino más bien una materia sobre la que habría que desconfiar para someterla a análisis desde el probabilismo y la filosofía natural. En primera instancia construye una definición de la comida diferenciándola de la bebida: la comida como parte activa, que da sustento, y la bebida como parte secundaria, pasiva y que funciona como vehículo de la comida. En cuanto a la comida, además de ser sustento, aclara Pinelo, que debía coincidir en cantidad y calidad suficientes para ser considerada tal. Estas variables son las que utiliza para llegar a su conclusión acerca del chocolate: que si bien es comida, no representa una cantidad suficiente, ya que hay parvidad de la materia y por lo tanto no quebranta el ayuno (Pinelo, 1636: 34). Acerca de las bebidas, aclara que muchas son artificiales, es decir por conmixtión, infusión o mezcla contienen muchos materiales y que son comestibles. Es decir que son comida más allá de su apariencia y sin embargo se las juzga como bebida por el hecho de ser líquido. La confusión así nacía por una impresión errónea y basada en el carácter extrínseco y superficial de la bebida. A diferencia del vino, la cerveza, la sidra o la aloxa, que son de carácter simple y natural, producidas por destilación, expresión o infusión, el chocolate, al ser elaborado por conmixtión, no perdía sus cualidades alimenticias.

Pinelo busca, además, ubicar los propósitos para los cuales se bebe el chocolate. Establece cuatro fines en los que se inscribe toda ingesta: 1) medicinal, 2) saciar la sed, 3) vicio, y 4) sustentar. Afirma: "todo lo que comemos o bebemos tiene estos fines" (Pinelo, 1636: 22). En cuanto al carácter medicinal, sostiene que la duda no entra en la polémica, ya que las medicinas no conciernen al problema del ayuno. Recurre al saber hipocrático para caracterizar al chocolate como una bebida esencialmente de carácter caliente y que, como efecto secundario, solamente calma la sed. Respecto a si se corresponde con un vicio, Pinelo sostiene que es distinto al tabaco, vino y otras bebidas, ya que no es embriagante. Aun así afirma que "en muchos lo debe ser" (Pinelo, 1636: 21) pero, en todo caso, es una característica secundaria, ya que el fin con el que se lo bebe y su principal característica y efecto es la de dar sustento al cuerpo. ${ }^{15}$

Heródoto, habla de una retórica de la alteridad donde se traduce al otro en los términos de la propia cultura del cronista. (Hartog, 2002: 29-30).

${ }^{15}$ Es interesante destacar que Pinelo desestima la posibilidad del vicio en el chocolate. En otros discursos de la época, la afición por el chocolate era vista como peligrosa, debido a su popularización tanto en Europa como en América y la sospecha de su consumo próximo a una dimensión de la sensualidad en relación con el goce del cuerpo (Norton, 2008). 
Resulta interesante la confluencia entre el discurso de Pinelo preocupado en resolver polémicas respecto a las bebidas desde el desmenuzamiento de sus confecciones, materiales, calidades y efectos, es decir, desde una mirada centrada en el orden natural- y el discurso teológico relativo al ayuno. Este entrecruzamiento no es casual sino más bien responde a una imagen del cuerpo normativizada. Visto como una prisión del alma, la renuncia al placer y la lucha contra las tentaciones hacían del cuerpo una esfera de corrupción, una dimensión sospechosa y a la cual había que renunciar en pos de un ideal ascético. Para tal fin, la Iglesia establecía un control del cuerpo en un calendario donde el ayuno y las restricciones alimenticias se desplegaban en una rutina de disciplinamiento de las prácticas (Le Goff y Truong, 2005). Cuerpo y alma, en el horizonte cultural de Pinelo, no estaban en absoluto separadas. Acerca del ayuno afirma: "La Iglesia en el ayuno, o para reparar la culpa, o para disponer la gracia, solo pretende mortificar y enflaquecer los cuerpos, para que menos llevadas de sus efectos queden más libres las almas" (Pinelo, 1636: 25). Así, los acontecimientos corporales encontraban un correlato espiritual siendo necesaria la codificación de las prácticas alimenticias y la reglamentación sobre los cuerpos (Le Goff y Truong, 2005: 55-56). El esfuerzo argumentativo de Pinelo va en esa dirección a partir de una explicación que utiliza elementos de la filosofía natural, la teoría humoral y las sagradas escrituras a fines de demostrar que la Iglesia normativizaba solamente el apetito de comida y no el apetito de bebida.

La inobservancia del precepto del ayuno, junto a la borrachera o la sexualidad, se ligaba directamente con los pecados de la gula y la lujuria. Es decir que eran una preocupación fundamental para el discurso teológico (Ferlan, 2018). Los llamados vicios carnales despojaban de la gracia al creyente estimulando la corrupción e impureza. La lucha contra las pasiones y la desconfianza en el cuerpo hacían del ayuno y la templanza una virtud y un remedio eficaz contra la corrupción. De todas las partes del cuerpo, la boca en particular era vista con desconfianza. El pecado de la gula significaba un sometimiento al mundo material y un descuido del alma. El placer desordenado, tanto en la bebida y la comida, eran signos de debilidad y alejamiento de Dios en oposición antitética a la embriaguez espiritual que suponía el encuentro con la divinidad (Corcuera de Mancera, 1997: 117-119). 


\section{Imagen 2}

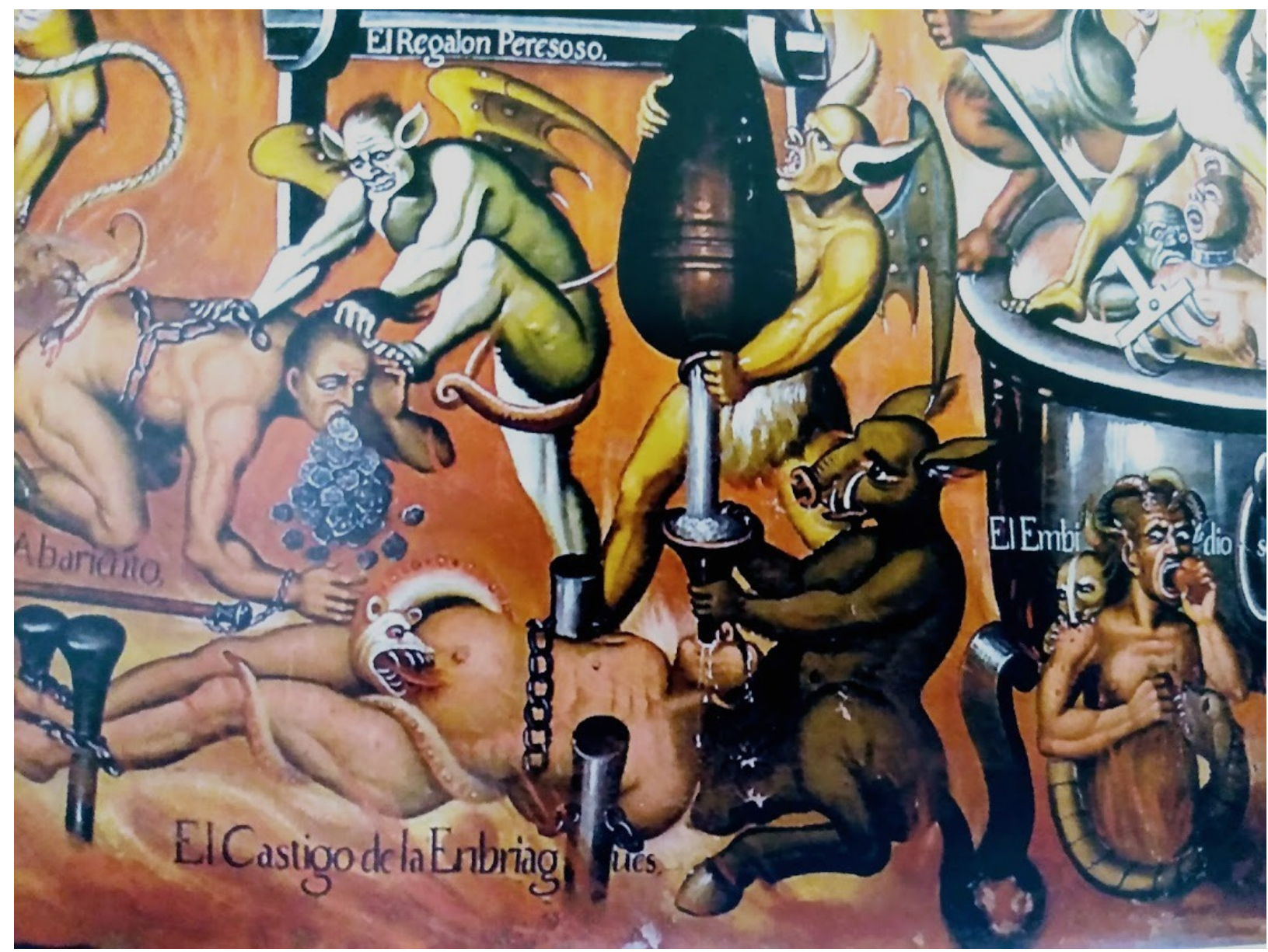

El infierno de la serie de las Postrimerías, (detalle) Iglesia de Caquiaviri, pintado en 1739, Autor anónimo, La Paz, Bolivia

En este sentido, no es menor la preocupación de Pinelo al escribir un tratado que, además de polemizar, apunta a facilitar la observancia de este santo precepto frente a un exuberante conjunto de materias naturales y bebidas que la conquista traía aparejado. La sospecha recaía también en un saber indígena del cual había que desconfiar, dado su carácter idolátrico. Ya en el prólogo de su tratado Pinelo advierte que en los territorios americanos cada uno sigue su conciencia. Respecto a la extensión del consumo de las bebidas y especies vegetales indianas escribía: "ha introducido el vicio o la costumbre en varias provincias de las Indias" (Pinelo, 1636: 34). Juzgando el origen de este problema, alega que la extensión de la costumbre de beber chocolate sin reparar en los días de ayuno había sido traspasada de los indígenas a los españoles a partir de dos figuras del sustrato subalterno de la sociedad colonial: "soldados sin letras" y "las mujeres en sus visitas" (Pinelo, 1636: 73-74). En un marco normativizado de las prácticas y representaciones en el contexto del proceso de confesionalización y al calor de la evangelización del Nuevo Mundo, esta 
situación generaba una esfera de tensiones que aguardaba respuestas y ordenamiento.

Cuestión moral entonces se extiende, además, a múltiples bebidas y plantas no solo por ser "materia poco tratada" (Pinelo, 1636: 149) sino por la necesidad que planteaba la emergencia de dichos consumos sin cuestionamiento ni determinación hasta ese entonces. El mismo método que Pinelo utiliza para el chocolate luego lo aplica extensivamente para una gran cantidad de bebidas advirtiendo: "cuál de los dos apetitos" satisfacen. Por ejemplo, al igual que Cárdenas, se pregunta acerca de la hoja de la coca pero en el caso de Pinelo el énfasis está puesto en su relación con el ayuno. En este caso se separa del discurso teológico discutiendo con el teólogo jesuita Martín del Río, quien había catalogado como supersticiosa la creencia acerca de que la coca quite el hambre. Para este último, esa propiedad solo podría corresponderse con una ilusión demoniaca. En cambio Pinelo, en concordancia con Cárdenas, explica que la hoja de la coca hacía desprender humores del estómago y, en cualquier caso, sería el mismo cuerpo que se autoconsume con su ingesta. Por lo tanto, en esta línea, la coca no daría sustento significativo, cerrando así toda posibilidad de entrada de lo sobrenatural. Pero también advierte que podía ser utilizada para no sentir el ayuno y en ese caso era un pecado venial. La coca es agrupada, junto a otras especies, como la hoja de betel de oriente, la hoja del nopal, el tabaco y el Coro. Pinelo extiende la resolución sobre la coca a estas especies y afirma que si bien mascadas dan sustento, este sería muy leve como para romper el ayuno. De todas formas la sospecha recae en ellas en la medida en que podrían servir para no sentir el hambre y por lo tanto defraudar la penitencia que el ayuno impone al cuerpo (Pinelo, 1636: 35-36).

Acerca de la yerba mate declara que, originaria del Paraguay, se ha extendido a todo el Perú e, incluso, entre los españoles. Descarta la posibilidad de quebrantar el ayuno eclesiástico, no así el ayuno moral, ya que no da sustento sino más bien que acrecienta el hambre, a contramano de la creencia de que posterga el apetito. Si bien su origen y utilidad sería medicinal, "por las flemas que arranca", Pinelo afirma: "ha dado en ser vicio, porque hay personas que la beben dos y tres veces al día, y se juntan a esto tan de propósito, y con tantas comodidades como para un convite, o recreación muy grande" (Pinelo, 1636: 34, 64-65).

Entre las muchísimas bebidas del Nuevo Mundo que nombra Pinelo se destacan el pulque mesoamericano y la chicha andina por la extensión y mayor profundidad del tratamiento que les brinda. Sobre el género de las chichas afirma que los indios del Perú quienes "por no carecer de bebidas artificial, inventaron algunas que se usaron, y usan hasta hoy con tanto exceso, que ha sido necesario darles modo" (Pinelo, 1636: 54). Este mismo tópico se repite acerca del pulque y en ambos casos la comparación obligada es una de las bebidas más importantes y conocidas del Viejo Mundo: el vino. Tanto para el 
caso del maíz y para el maguey, que son las materias primas fundamentales de la chicha y el pulque respectivamente, Pinelo se muestra entusiasta respecto a sus múltiples usos y sus calidades. De ambas bebidas reconoce su extensión, también entre los españoles, e introduce distinciones entre las formas de consumo propiamente indígenas. En la mayoría de las preparaciones que son abordadas en Cuestión moral afirma que, al no ser sustanciosas, no quebrantarían el ayuno. Sin embargo, Pinelo advierte acerca del uso indígena refiriendo al problema de la idolatría y el lugar central que ocupaban los distintos tipos de chichas en la religiosidad andina. Retomando al extirpador de idolatrías del Perú, el jesuita Pablo Joseph de Arriaga, Pinelo afirma sobre la chicha: "que la principal ofrenda, y a mayor parte de los sacrificios de aquellos indios es la Chicha que por ella, y con ella comienzan todas las fiestas de las huacas, que son sus ídolos, en ella median, y en ella acaban, y es el todo. Y así tienen para hacerla ministros, y supersticiones particulares" (Pinelo, 1636: 57). ${ }^{16}$

A su vez, diferencia distintas preparaciones propiamente indígenas de las chicha y describe la ingesta indígena en los siguientes términos: "La segunda usan los Indios comúnmente en sus fiestas, convites, y bebidas ordinarias (...) queda hecha bebida, que embriaga, siendo mucha, y nunca ellos se contentan con poca; por lo que no hay fiesta en que no queden todos caídos hasta la mañana." (Pinelo, 1636: 57).

Estos mismos términos se repiten en el tratamiento del pulque que usan los indígenas de Nueva España. Por un lado se destacan las distintas preparaciones y utilidades del maguey: extraer hilo, papel, azúcar, madera, miel, conservas y su carácter medicinal. Por el otro lado, Pinelo advierte sobre los usos propiamente indígenas de esta planta. En este último caso, describe, retomando al franciscano Motolinía, la preparación del pulque en conjunto con el uso de una raíz llamada ocpatl (Acacia angustissima):

"Solían los indios al cocerle echarle unas raíces, que llaman ocpatl, que significa adobo de vino, con la que le dejaban tan fuerte, que con muy poca cantidad se embriagaban para dos y tres días, quedando tan furiosos y terribles, que se herían, mataban, y cometían infinitas torpezas, sin acuerdo, ni juicio, y les parecía que se los comían de gusanos, y que los acometían serpientes, tigres, y otros animales feroces" (Pinelo, 1636: 30).

Tanto en este último caso, como para las sesiones de bebida de la chicha, utiliza a las antiguas culturas gentiles del Viejo Mundo, específicamente a los

\footnotetext{
16 Prácticamente Pinelo parafrasea a Arriaga quien afirmaba sobre la chicha como "Principal ofrenda y la mejor, y la mayor parte de sus sacrificios, es la chicha por ella, y con ella comienzan todas las fiestas de las Huacas, en ella median, y en ella acaban, sus fiestas, y ella es el todo. Y así tienen para este efecto muchos vasos, y vasijas de diferentes formas, y materias, y es común modo de hablar, que dan de beber a las Huacas" (Arriaga, [1621] 1920:42).
} 
escitas y a los tracios, como analogía para representar el consumo indígena de bebidas embriagantes. Afirma: "Parece imitaban los Indios a los antiguos, que para aumentar la fuerza del vino le echaban la hierba, que llamaban buglosa, o nepentes" (Pinelo, 1636: 30). Esta referencia de los antiguos, a partir de la cual Pinelo traduce la alteridad, establece un puente temporal en el que el Nuevo Mundo es el lugar donde, mediante los nativos, se verifica a los antiguos. El alejamiento espacial se traduce y recurre en un alejamiento temporal para desencantar los confines de una nueva geografía (Hartog, 2005).

En una dirección similar describe los usos indígenas del cebil para las regiones de Tucumán y Paraguay:

"Muelen esta semilla, y encerrados en buhío, o casa sin respiradero, y con gran fuego en medio, bebe cada uno por las narices una onza de su polvo [...] Basta saber que con esto quedan cuantos le toman como muertos por espacio de dos, o tres horas, en el buhío cerrado y con lumbre, que es milagro que vuelvan en sí" (Pinelo, 1636: 42).

Incluso parecería asociar la posibilidad del uso del cebil con la brujería o la hechicería: "Para peores cosas usan algunas Indias aun Españolas esta semilla" (Pinelo, 1636: 42). Aun así, a pesar de la carga negativa con la que se la representa, rescata esta última materia vegetal como medicinal: "No es comida, ni bebida, sino medicamento, aunque fuerte, vicioso, bárbaro y de notable riesgo para los que lo han acostumbrado" (Pinelo, 1636: 42).

Tanto para estas últimas materias y bebidas, así como para el caso del chocolate, además de trazar una posición respecto al precepto del ayuno, Pinelo nos brinda una clara imagen del universo de significación con el que se quisieron traducir las prácticas culturales de las poblaciones indígenas. De alguna manera la fórmula se repite y se muestra con meridiana claridad cuando describe los consumos de bebidas y especies que hoy en día llamaríamos psicoactivas. La embriaguez en términos del discurso teológico era concebida como un pecado grave opuesto a la templanza en tanto virtud. Cercana a la gula y a la lujuria, la embriaguez se correspondía con un placer desordenado y atravesado por la pérdida de la razón y por lo tanto con el alejamiento de la gracia divina (Corcuera de Mancera, 1997).

En este sentido, el recurrente estereotipo del bárbaro empalma con una representación de la embriaguez de tipo apóstata. La noción de la barbarie tuvo un carácter maleable y fue un vehículo para representar la alteridad indígena. Esta imagen que retoma Pinelo sirve para delimitar y distinguir al interior del mundo colonial las formas legítimas e ilegítimas de relacionarse con bebidas y materias naturales. El bárbaro, en este caso, se caracteriza por una inferioridad cultural que se expresa concretamente en sus sesiones de bebidas que en 
muchísimas fuentes son mencionadas como juntas. ${ }^{17}$ En términos de Ginzburg el carácter ritual de estas ingestas provoca en el observador europeo una inversión del signo a partir del cual se pasa de destacar sus virtudes a ver en su uso indígena pruebas de idolatría (Ginzburg, 2010: 146). De esta forma, el consumo de bebidas embriagantes por parte de las poblaciones indígenas es representado por la incapacidad de moderación, por la incapacidad de controlar una naturaleza cercana a lo animal y por lo tanto, incapaces de virtud más cercanos a lo bestial que a lo racional.

\section{Palabras finales}

Ambos tratados analizados forman parte del horizonte cultural de la temprana edad moderna, marcado por la intensificación de las interacciones entre distintos pueblos del mundo y un profundo cambio cultural. Parten de poderosos modelos establecidos por autores clásicos y participan en la circulación de saberes de su época. También dialogan con autores modernos tales como Laguna, Arriaga, Acosta, García da Orta, entre otros. En conjunto forman parte del proceso de planetización de los autores clásicos durante la primera mundialización (Gruzinski, 2010: 53). Existe, en ambos, una tensión entre los elementos conocidos de sus propias tradiciones culturales y la circulación de nuevos materiales provocada por el creciente contacto con otras culturas durante la exploración interoceánica.

Por un lado dan cuenta de una conciencia de la ampliación de la realidad. Por otro lado, la necesidad de definir cuál es el lugar que estas plantas y bebidas deben tener -si aceptable o deplorable- en la cultura del colonizador. En efecto, ambos tratados funcionan como mediadores entre mundos. Sus objetivos son esclarecer los secretos que dichos elementos encierran y, en simultáneo, refutar las opiniones, los usos y los rumores en torno a estos que podían ser equívocos, supersticiosos o idolátricos. Asimismo, las plantas y bebidas americanas estaban rodeadas de un halo cultural indígena que necesitaba ser domesticado para su incorporación por los europeos. Se correspondían con determinadas prácticas y saberes que bajo la mirada del discurso teológico y la evangelización entraban en contacto con lo idolátrico. Es decir, contenían un fuerte arraigo en la esfera cultural de lo sobrenatural indígena.

Tanto Cárdenas como Pinelo, cada uno a su manera, son mediadores entre las experiencias nativas acerca de las plantas y bebidas americanas y la cultura letrada europea a partir de una "retórica de la alteridad" (Hartog, 2002: 30). Los dos traducen y apropian, bajo códigos y dispositivos de saber-poder y,

\footnotetext{
17 Existe numerosa bibliografía acerca de este tema, algunos trabajos que tomamos como referencia son: Saignes (1993); Corcuera de Mancera (1997); Paz (2017).
} 
en el mismo acto que dan a conocer, silencian las tradiciones indígenas y la autoridad de los especialistas indígenas acerca de dichos materiales. Es decir, la comprensión y apropiación de las novedades indianas a partir de estas historias naturales tuvieron un anclaje político en la medida en que eran apropiadas dentro de un sistema que se proyectaba como único y universal (Olarte Nieto, 2009: 14). Cárdenas y Pinelo representan un esfuerzo por descifrar, delimitar y adecuar la novedad americana a las reglas de un orden natural concebido como universal y donde aún confluían el discurso teológico y la filosofía natural.

Buenos Aires, febrero de 2020.

\section{Bibliografía citada}

Aguirre Beltrán, Gonzalo (1963). Magia y medicina. El proceso de aculturación en la estructura colonial, México: Fondo de Cultura Económica.

Arriaga, Joseph Pablo ([1621] 1920). La extirpación de la idolatría en el Perú, Lima: Librería Sanmarti, $1920 . \quad$ Recuperado de: http://bibliotecadigital.aecid.es/bibliodig/es/consulta/registro.cmd?id=238

Bernand, Carmen y Gruzinski, Serge (1992). De la idolatría: una arqueología de las ciencias religiosas, México: Fondo de Cultura Económica.

Campagne, Fabián Alejandro (2002). Homo catholicus. Homo superstitiosus. El discurso antisupersticioso en la España de los siglos XV y XVIII, Madrid: Miño y Dávila.

Cañizares Esguerra, Jorge (2007). Católicos y puritanos en la colonización de América, Madrid: Marcial Pons.

Cárdenas, Juan de ([1591] 1988). Problemas y secretos maravillosos de las Indias, Madrid: Alianza.

Cook, Harold J. y Walker, Timothy D. (2013). “Circulation of Medicine in the Early Modern Atlantic World", en Social History of Medicine, Volume 26, Issue 3, August 2013, pp. 337-351.

Corcuera de Mancera, Sonia (1997). El fraile, el indio y el pulque. Evangelización y embriaguez en la Nueva España de (1523-1548), México: Fondo de Cultura Económica.

Daston, Lorraine y Park, Katharine (1998). Wonders and the Order of Nature 11501750, New York: Zone Books.

Egaña Rojas, Daniel (2015). “Comerse las Indias. La alimentación como clave clasificatoria del Nuevo Mundo en la obra de Fernández de Oviedo", en Anuario de Estudios Americanos, núm. 72, pp. 579-604. 
Elliott, John Huxtable (1976). "Renaissance Europe and America: A Blunted Impact?", en Chiappelli, Fredi (ed.) First Images of America. The Impact of the New World on the Old, Berkeley: University of California Press, pp. 11-23.

Ferlan, Claudio (2018). “El ayuno eclesiástico", en Max Planck Institute for European Legal History Research Paper Series, núm. 2018-09. Recuperado de: https://papers.ssrn.com/sol3/papers.cfm?abstract $\mathrm{id}=3260582 \# \#$

Foucault, Michael (2008). La vida de los hombres infames, Buenos Aires: Altamira.

Ginzburg, Carlo (2010). El hilo y las huellas. Lo verdadero, lo falso, lo ficticio, Buenos Aires: Fondo de Cultura Económica.

Grafton, Anthony (1992). New Worlds Ancient Texts. The power of tradition and the Shock of Discovery, Cambridge: Harvard University Press.

Greenblatt, Stephen (2008). Maravillosas posesiones: el asombro ante el Nuevo Mundo, Barcelona: Marbot.

Gruzinski, Serge (2010). Las cuatro partes del mundo. Historia de una mundialización, México: Fondo de Cultura Económica.

Hartog, François (2002). El espejo de Heródoto. Ensayo sobre la representación del otro, Buenos Aires: Fondo de Cultura Económica.

Hartog, François (2005).Anciens, modernes, sauvages, París: Galaade Éditions.

Hernández Triviño, Ascensión (2013). "Chocolate: historia de un nahuatlismo", en Estudios de cultura náhuatl, núm. 46, pp. 34-87.

Imolesi, María Elena (2018). "Soluciones jesuitas en entornos misionales: la aplicación del probabilismo en la resolución de dudas en torno a los matrimonios en las reducciones de guaraníes", en Historia y Grafía, núm. 50, pp. 57-84.

Kupperman, Karen Ordahl (1995). “The changing definition of America”, en Kupperman, Karen Ordahl (ed.) America in European Consciousness, Chapel Hill: University of North Carolina Press, pp. 1-29.

Le Goff, Jacques; Truong, Nicolas (2005). Una historia del cuerpo en la Edad Media, Barcelona: Paidós.

León Pinelo, Antonio de (1636) Questión moral si el chocolate quebranta el ayuno eclesiástico, Madrid.

Martínez, Carolina (2016). “Relatos de viaje e imaginarios geográficos en la Cosmografía Universal (1556) de Guillaume Le Testu: apuntes para una arqueología textual", en: Magallánica: revista de historia moderna, núm. 4, vol. 2, pp. 118-135. 
Mayer Celis, Leticia (2011). "La corriente moral del probabilismo y su influencia en la génesis de las ideas científicas de probabilidad", en Estatística e Sociedade, núm. 1, pp. 65-85.

Norton, Marcy (2008). “Chocolate para el imperio: la interiorización europea de la estética mesoamericana", en Revista de Estudios Sociales, núm. 29, pp. 42-69.

Norton, Marcy (2008). Sacred Gifts, Profane Pleasures: A History of Tobacco and Chocolate in the Atlantic World, New York: Ithaca, Cornell Universtity Press.

Olarte Nieto, Mauricio (2009). “Ciencia, imperio, modernidad y eurocentrismo: el mundo atlántico del siglo XVI y la comprensión del Nuevo Mundo", en Historia Crítica, núm. 1, pp. 12-32.

Pagden, Anthony (1988). La caída del hombre natural: el indio americano y los orígenes de la etnología comparativa, Madrid: Alianza Editorial.

Pagden, Anthony (1993). European Encounters with the New World: from Renaissance to Romanticism, New Haven \& London: Yale University Press.

Pardo-Tomás, José (2002). El tesoro natural de América. Colonialismo y ciencia en el siglo XVI, Madrid: Nivola.

Pardo-Tomás, José (2004). "Diablos y diabluras en la literatura de secretos", en Tausiet María y Amelag, James (eds.) El diablo en la Edad Moderna, Madrid: Marcial Pons, pp. 297-325.

Pardo-Tomás, José (2011). “Natural knowledge and medical remedies in the book of secrets. Uses and appropriations in Juan de Cárdenas "Problemas y secretos maravillosos de las Indias" (México, 1591)", en Anagnostou, S., Egmond, F. y Friedrich, E. (eds.) Passions for Plants: Materia Medica and Botany in Scientific networks from the 16th to 18th Century, Stuttgart: Wissenschafliche verlagsgesellschaft, pp. 93-108.

Paz, Carlos (2017). “La borrachera y sus pre-textos. El beber indígena en la literatura jesuítica sobre Chaco del siglo XVIII", en Revista Brasileira de História E Ciências Sociais, núm. 17, pp. 50-72.

Saignes, Thierry (1993). “Borracheras andinas: ¿Por qué los indios ebrios hablan español?", en Saignes, Thierry (dir.) Borrachera y memoria. La experiencia de lo sagrado en los Andes, Lima: Hisbol/IFEA pp. 43-72.

Schwartz, Stuart (1994). "Introduction", en Schwartz, Stuart (ed) Implicit understandings. Observing, Reporting, and Reflecting Encounters between Europeans and Other Peoples in the Early Modern Era, Cambridge: Cambridge University Press. 